\title{
Riscos e potencialidades na expansão dos cursos de licenciatura em Educação do Campo
}

\author{
Risks and potentialities in expansion of the degree courses in Rural Education \\ Riesgos y potencialidades en la expansión de los cursos de profesorado en \\ Educación del Campo \\ MÔNICA CASTAGNA MOLINA \\ SALOMÃO MUFARREJ HAGE
}

Resumo: O artigo analisa as Licenciaturas em Educação do Campo enquanto política pública conquistada pelo campesinato, referenciando-se nas categorias do materialismo histórico dialético. Através de pesquisa bibliográfica, documental e de campo, buscou-se compreender riscos e potencialidades no processo de institucionalização destes cursos. A análise priorizou o ingresso dos camponeses na Educação Superior; a concepção da Alternância Pedagógica nos cursos e a consolidação da Educação do Campo como área de produção de conhecimento, evidenciando situações capazes de maximizar ou descaracterizar os efeitos dessa política.

Palavras-chave: Educação superior; educação do campo; políticas públicas.

Abstract: This article analyzes the degree in Rural Education Courses as a public policy conquered by the peasants' social movements, by referring in the categories of dialectical historical materialism. Through bibliographical, documentary and field research, we tried to understand the risks and potentialities in the process of institutionalization of these courses. The analysis prioritized the entrance of peasants in Higher Education; the conception of Educational Alternating in the courses and the consolidation of Rural Education as a knowledge production area, revealing situations that can disfigure or maximize the effects of this policy.

Keywords: Higher education; rural education; public policy.

Resumen: El artículo analiza los profesorados em Educación del Campo como una política pública conquistada por los movimientos campesinos, refiriéndose a las categorías del materialismo histórico dialéctico. Por medio de Investigación bibliográfica, documental y de campo, se buscó comprender riesgos y potencialidades en el proceso de institucionalización de estos cursos. El análisis dio prioridad a la entrada de los campesinos a la educación superior; la concepción de alternancia pedagógica en los cursos y la consolidación de la Educación del Campo como área de producción de conocimiento, revelando situaciones capaces de maximizar o descaracterizar los efectos de esta política.

Palabras clave: Educación superior; educación del campo; políticas públicas. 


\section{INTRODUÇÃO}

O presente artigo tem sua origem na pesquisa "Políticas de Expansão da Educação Superior no Brasil”, em execução de 2013 a 2017, e desenvolvida no âmbito do Observatório da Educação, da Coordenação de Aperfeiçoamento de Pessoal de Nível Superior (CAPES). Integrada por sete subprojetos e realizada articuladamente por pesquisadores de diversas Instituições de Ensino Superior (IES), a referida pesquisa objetiva analisar as políticas de expansão da Educação Superior no país, a partir de 1995, considerando as mudanças econômicas, políticas e sociais em curso e as reformas institucionais advindas da Reforma do Estado brasileiro.

Entre os sete subprojetos mencionados, a pesquisa em questão tem sido desenvolvida pelo Sub 7, reunindo o grupo de pesquisadores que analisa a expansão da Educação Superior do Campo e suas contribuições para o desenvolvimento rural e para a sociedade nacional. Ela parte da premissa de que uma das frentes em que vem ocorrendo a expansão da Educação Superior do Campo é no âmbito da formação de educadores, com a implementação de cursos permanentes de "Licenciatura em Educação do Campo" (LEDOC), em IES brasileiras (MOLINA, 2015 ; MOLINA \& HAGE, 2015).

Os cursos de Licenciatura em Educação do Campo constituem uma modalidade de graduação nas universidades públicas brasileiras que objetivam formar e habilitar profissionais para atuação nos anos finais do Ensino Fundamental e Ensino Médio, por área de conhecimento e também para a gestão de processos educativos escolares e processos educativos comunitários. Eles foram implementados no âmbito do PROCAMPO, que no entendimento de Molina e Hage (2015, p. 17), constitui-se como uma política de formação de educadores, conquistada a partir da pressão e das demandas apresentadas ao Estado pelos movimentos sociais, a partir do Decreto $\mathrm{n}^{\circ}$ 7.352/2010 (BRASIL,2010), que instituiu a Política Nacional de Educação do Campo. O Programa tem se transformado numa política estruturante de formação de educadores, especialmente com o Edital no 02/2012 da SECADI/MEC (BRASIL, 2012), que aprovou 42 projetos a serem desenvolvidos em IES, com disponibilização de 600 vagas permanentes para docentes e 126 técnicos nessas instituições e com a meta de formar 15 mil professores para atuar na Educação Básica, nas escolas do campo, nos primeiros três anos dos cursos.

A Licenciatura em Educação do Campo possui uma proposta curricular integrada e referenciada na Alternância Pedagógica e organiza os componentes curriculares em quatro áreas do conhecimento: Linguagens (expressão oral e escrita em Língua Portuguesa, Artes, Literatura); Ciências Humanas e Sociais; 
Ciências da Natureza e Matemática, e Ciências Agrárias, buscando superar a fragmentação tradicional que dá centralidade à forma disciplinar e incidir no modo de produção do conhecimento na universidade e na escola do campo, tendo em vista a compreensão da totalidade e da complexidade dos processos encontrados na realidade.

Neste artigo objetivamos reunir evidências que possam referenciar as questões que temos pautado na pesquisa do Sub 7, organizadas em dois eixos, quais sejam: apresentar elementos teóricos dos PPC das universidades que ofertam a LEDOC, que indicam a possibilidade de essa política de formação de educadores significar um espaço de acúmulo de forças e de desenvolvimento de experiências, que possam ampliar os espaços de práticas de formação de educadores como sujeitos históricos sociais capazes de formar novas gerações de jovens e adultos, numa perspectiva humanista e crítica. Busca-se, anda, explicitar que as práticas formativas desenvolvidas nessas graduações, face a sua vinculação material de origem, podem enfrentar a hegemonia das atuais políticas de formação no Brasil, orientadas predominantemente pela chamada "Epistemologia da Prática", fortalecendo e disseminando processos formativos baseados na "Epistemologia da Práxis". (MOLINA \& HAGE, 2015).

As reflexões que compõem este artigo se fundamentam em levantamento documental, no qual analisamos dissertações, teses, artigos e legislação que referenciam a formação de educadores do campo, assim como relatórios, notas técnicas e produções de reuniões e Seminários Nacionais das LEDOC. Referenciam, ainda, as discussões aqui apresentadas os resultados do estudo de campo que têm sido desenvolvido em conjunto com dez Universidades ${ }^{1}$ que ofertam o Curso e que integram o Sub 7, buscando compreender como tem se materializado, no processo de institucionalização da Licenciatura em Educação nessas instituições os riscos e potencialidades elencados como elementos capazes de descaracterizar ou de maximizar os efeitos dessa política pública de formação de educadores, conquistada pela luta do movimento camponês na disputa por outro projeto de campo, de educação e de sociedade.

Nesses estudos temos procurado observar e analisar os riscos de descaracterização dessa política de formação de educadores, a partir do movimento de expansão para oferta desses 42 cursos permanentes, quais sejam: promoção do ingresso dos sujeitos camponeses na Educação Superior; garantia

1 As dez Universidades que integram a pesquisa são: Universidade Federal do Pará (Campus Cametá), Universidade Federal do Sul e Sudeste do Pará e Universidade Federal do Tocantins (Campus de Tocantinópolis), na Região Norte; Universidade Federal do Recôncavo da Bahia e Universidade Federal do Maranhão, na Região Nordeste; Universidade de Brasília (Campus Planaltina), na Região Centro-Oeste; Universidade Federal Rural do Rio de Janeiro e Universidade Federal de Viçosa, na Região Sudeste; Universidade Federal de Santa Catarina e Universidade Federal da Fronteira Sul, na Região Sul. 
do protagonismo dos movimentos sociais do campo na sua execução; vínculo orgânico com as lutas e com as escolas do campo; materialização a partir da alternância pedagógica; e formação do trabalho docente multidisciplinar, a partir das áreas de conhecimento.

Da mesma forma, temos procurado observar e analisar as potencialidades que emergem da ampliação da oferta desses cursos, a saber: a consolidação da Educação do Campo como área de produção de conhecimento; acúmulo de forças para conquista de novas políticas públicas; desencadeamento de novas lógicas para organização escolar e método do trabalho pedagógico nas escolas do campo; ampliação do acesso e do uso de novas tecnologias nas escolas do campo. É fundamental destacar que os riscos e potencialidades de ampliação das LEDOC em nossos estudos encontram sentido condicionados pela totalidade maior que os contém: as tensões e contradições vivenciadas no campo pela intensíssima expansão do modelo agrícola hegemônico estruturado a partir do agronegócio e, também, nas tensões e contradições presentes na expansão da Educação Superior no Brasil (MOLINA, 2015).

Para dar conta de nossos propósitos, organizamos o texto em três sessões que se articulam e se complementam na reflexão sobre os riscos e potencialidades na institucionalização dos cursos de Licenciatura em Educação do Campo, a partir do movimento de expansão para oferta dos 42 cursos permanentes. No entanto, dada a impossibilidade de tratar de todos eles com a profundidade exigida, em face dos limites de extensão do artigo, priorizamos a explicitação e análise de três pontos: a promoção do ingresso dos sujeitos camponeses na Educação Superior; a materialização dos cursos a partir da Alternância Pedagógica e a consolidação da Educação do Campo como área de produção de conhecimento. Evidenciamse situações capazes de maximizar ou descaracterizar os efeitos dessa política, os quais constituem os temas abordados nas próximas sessões do texto.

\section{INGRESSO DOS SUJEITOS CAMPONESES NOS CURSOS DE LICENCIATURA EM EDUCAÇÃO DO CAMPO}

A criação dos cursos de Licenciatura em Educação do Campo remete às demandas das lutas por terra e educação, protagonizada pelos movimentos sociais desde a I Conferência Nacional por Uma Educação Básica do Campo (1988) e da II Conferência Nacional de Educação do Campo (2004), em que se vai desenhando uma política pública para garantir a formação de educadores que atuam nos territórios rurais.

A implantação desta política se deu através de uma experiência piloto ofertada por quatro universidades: UFMG, UnB, UFBA e UFS; e posteriormente 
com o lançamento de editais em 2008 e 2009 pelo MEC para que outras instituições ofertassem o curso através de projetos especiais autorizados somente para uma turma e sem garantia de continuidade e permanência. (MOLINA; HAGE, 2015) Com o Decreto no 7.352/2010 (BRASIL, 2010), que instituiu a Política Nacional de Educação do Campo e definiu metas específicas para a formação de educadores, essa política de formação foi tornando-se estruturante e expandindo a Educação Superior no campo, especialmente com o Edital no 02 de 31/08/2012 (BRASIL,2012) vinculado à SESU/SETEC/SECADI/MEC, que aprovou a oferta do Curso de Licenciatura em Educação do Campo com turmas regulares e com vagas para docentes e servidores permanentes, conforme afirmamos anteriormente.

Esse cenário de expansão e de institucionalização das Licenciaturas em Educação do Campo enseja a necessidade de análise de pontos fundamentais para cumprimento dos objetivos que lhes deram origem. Entre eles, investigar se, de fato, tem-se mantido nos cursos estratégias de ingresso que garantam o acesso dos sujeitos camponeses à Educação Superior, considerando-se a extrema desigualdade na quantidade e qualidade de oferta da Educação Básica aos povos do campo, fator histórico que não pode ser minimizado.

A realização de pesquisa documental nos editais de seleção nos propiciou identificar que, nos primeiros anos de implantação, as IES estudadas têm conseguido enfrentar e superar um dos maiores riscos de descaracterização dessa política pública, que se traduziria na mudança do perfil dos ingressantes nos cursos. O enfrentamento desse risco tem-se dado a partir de ampla articulação interna dos docentes, que têm realizado intensos enfrentamentos administrativos e financeiros no interior das universidades para que se mantenham os Processos Seletivos Especiais (PSE), com notas de corte diferenciadas, objetivando garantir o ingresso da juventude camponesa e de educadores das escolas do campo nos cursos.

Os PSE realizados pelas IES que integram a pesquisa apresentam estratégias variadas, envolvendo diferentes fases: provas de múltipla escolha, elaboração de redação, produção de memorial, realização de entrevista, comprovação de moradia e de trabalho no campo. Mas, todas elas, com a intencionalidade de garantir de fato o acesso dos sujeitos do campo a essa graduação específica. O Decreto $\mathrm{n}^{\circ}$ 7.352/2010 (BRASIL, 2010), em seu artigo $1^{\circ}$, estabelece os parâmetros para o atendimento à Educação Básica e à Educação Superior no campo e define os sujeitos do campo a partir de sua sociodiversidade.

A política de Educação do Campo destina-se à ampliação e qualificação da oferta de educação básica e superior às populações do campo, e será desenvolvida pela União em regime de colaboração com os Estados, o Distrito Federal e os Municípios, de 
acordo com as diretrizes e metas estabelecidas no Plano Nacional de Educação e o disposto neste Decreto. [...] \10 Para os efeitos deste Decreto, entende-se por: [...] I - populações do campo: os agricultores familiares, os extrativistas, os pescadores artesanais, os ribeirinhos, os assentados e acampados da reforma agrária, os trabalhadores assalariados rurais, os quilombolas, os caiçaras, os povos da floresta, os caboclos e outros que produzam suas condições materiais de existência a partir do trabalho no meio rural... (Art. $1^{\circ}$ )

As disputas internas nas universidades, que normalmente põem de um lado os coordenadores do curso e o coletivo de educadores e, de outro, a administração central e as Procuradorias Jurídicas, têm enfrentado duas ordens de questões diferenciadas: uma, a da própria concepção do direito a uma seleção específica para os sujeitos camponeses, sob a alegação da restrição do princípio da isonomia e do amplo acesso às universidades públicas, que ignora todo o debate e jurisprudência existentes sobre a necessidade de políticas afirmativas para determinados grupos sociais em função da histórica privação de direitos a que foram submetidos; a outra, referente aos custos desses Processos Seletivos Especiais, que ocorrem em datas e locais diferenciados, exigindo pessoal e recursos materiais extras das universidades para ofertá-los.

Faz-se importante destacar que as coordenações e os coletivos de educadores, em parceria com os movimentos sociais, têm desempenhado relevante papel nessa resistência conseguido relativo êxito nesse processo institucional, organizando argumentos e produzindo documentos para a defesa, todas as vezes que esta problemática volta à cena, o que tem sido bastante frequente.

Consideramos relevante, ainda, para o êxito dessa política pública, entendida como um dos principais riscos que os cursos vêm enfrentando nesse contexto de ampliação e institucionalização, apresentar relatos das IES integrantes da pesquisa, que apresentam estratégias adotadas para a garantia de ingresso dos sujeitos camponeses na educação superior. A seguir o texto da UFRRJ:

Para garantir que os diversos sujeitos do campo tenham acesso ao curso, o processo seletivo discente, via edital público é composto por provas de conhecimentos culturais e gerais, uma redação sobre temas específicos da realidade brasileira e um Memorial sobre seu percurso de vida e formação. Este acesso especial se justifica na medida em que o potencial estudante da Licenciatura em Educação do Campo tem, em geral, um percurso formativo bastante deficitário, principalmente a parcela do público de mais idade que concluiu o ensino médio em cursos aligeirados, com longas interrupções durante este acidentado caminho de escolarização. [...] Neste sentido, o acesso via Exame Nacional do Ensino Médio (ENEM) poderia atrair para o curso sujeitos que nada têm a ver com a origem sociocultural que se pretende atingir. Sob este aspecto, além de demonstrar seus conhecimentos oriundos do ensino médio, é de extrema centralidade no processo seletivo o Memorial, instrumento avaliado pelos próprios docentes desta Licenciatura, que considera a história de vida do candidato/a, seu engajamento atual e futuro com as lutas sociais 
e o enfrentamento político para que a Educação do Campo se efetive plenamente como um direito educacional. Para tanto, os critérios de seleção para o ingresso no curso apoiam-se no seguinte perfil: 1) moradores e pequenos agricultores de áreas rurais, comunidades quilombolas e caiçaras; 2) em condição de vulnerabilidade social e econômica; 3) que desenvolvam atividades com comunidades populares, do campo, quilombolas ou indígenas voltadas à diversidade sociocultural; 4) que pratiquem agricultura ecológica em espaços urbanos; 4) oriundos de escola pública; 5) que os pais não tenham o ensino superior e 6) professores/as da rede pública que atuam nas escolas do campo e não tenham a certificação do ensino superior. (SANTOS; ABBONIZIO, 2016, p. 1633)

O relato da experiência da UNIFESSPA também é significativo; tendo enfrentando sérios problemas no ingresso da primeira turma, conseguiu, face à articulação com os movimentos sociais e o coletivo de educadores, pressionar a universidade para a mudança no processo seletivo assegurando nos editais as especificidades para garantia do ingresso dos sujeitos do campo.

Em 2009, a primeira seleção foi através do processo seletivo edital n. 02/2009 realizado pelo Centro de Processos Seletivos (CEPS) [...]. A primeira turma foi formada por uma parcela de estudantes vinculada às comunidades camponesas e outra não oriunda das populações rurais, que, pelas suas histórias sócio-política (sic), não se identificaram com a proposta do curso. Assim, houve um alto índice de desistência de vagas e de transferência para outros cursos. Foram trinta estudantes aprovados para o ingresso e apenas treze concluíram o percurso formativo. Após esse resultado inicial, foi constatado que era necessário construir processos seletivos que permitissem a inclusão das populações do campo, público alvo do curso. Após amplo debate, foi acordado o ingresso através de Processo Seletivo Especial (PSE), composto por duas fases: a primeira, composta por uma prova de conhecimentos gerais e uma redação, e a segunda, por entrevistas [...]. No primeiro edital de 2010, foi expresso o público alvo do curso: destina-se, portanto, a formar professores para atuar na Educação do Campo, dando prioridade aos candidatos que já atuam em processos educativos vinculados ao campo, mas que não possuem ainda qualificação em nível superior, e aos que vivem no campo e/ou pertençam a Comunidades do Campo [...]. A partir de 2010, as turmas foram formadas com o perfil delineado em Edital, pois adentraram ao ensino superior estudantes de comunidades ribeirinhas, agricultores familiares, professores das escolas do campo; quilombolas e um indígena da aldeia Kayapó, ampliando assim a diversidade atendida pelo curso. Esses alunos se tornaram os maiores divulgadores da proposta do curso. (ANJOS; SILVA; MOLINA, 2016, p. 1831).

O processo de institucionalização dos cursos implica a reflexão e definição coletiva acerca de critérios que serão consolidados para o ingresso dos estudantes, considerando seus propósitos e finalidades; a experiência da UFRRJ contribui para essa discussão quando indica condicionantes que reforçam o perfil dos sujeitos que se pretende atender nessas Licenciaturas, assentadas em três perspectivas: a) pertencimento ao território/territorialidade - moradores e pequenos 
agricultores de comunidades rurais, quilombolas e caiçaras, ou que pratiquem agricultura ecológica em espaços urbanos; b) base profissionall formativa - professores da rede pública que atuam nas escolas do campo sem graduação, e sujeitos que desenvolvam atividades educativas com comunidades do campo, quilombolas ou indígenas, voltadas à diversidade sociocultural; c) situação socioeconômica - sujeitos oriundos da escola pública, que os pais não possuem ensino superior e que vivem em condição de vulnerabilidade social e econômica.

As experiências de ambas as universidades revelaram, ainda, a necessidade de se contrapor aos processos convencionais de ingresso dos estudantes nas IES via Exame Nacional do Ensino Médio (ENEM), que atrai para o curso sujeitos que pouco tem a ver com a origem sociocultural que se pretende atingir, ou seja, estudantes não oriundos das populações rurais, que evadem ou solicitam transferência para outros cursos por não se identificarem com a Licenciatura em Educação do Campo. Tem-se realizado o enfrentamento ao sistema de acesso que se referencia no mérito, que reforça a exclusão dos sujeitos ao ensino superior, seja por classe social, raça, gênero, territorialidade ou deficiência. Também o sistema de cotas e reserva de vagas, enquanto referência de acesso, não tem dado conta da demanda específica de ingresso dos estudantes que se pretende atingir nos cursos de Licenciatura em Educação do Campo.

Os Gráficos 1 e 2, a seguir, apresentam respectivamente o número de vagas ofertadas pelos Cursos de Licenciatura em Educação do Campo a partir do Edital de 2012 até o ano de 2015, e o número de vagas ocupadas pelos estudantes destas graduações até 2015, que, quando comparadas entre si, permitem-nos algumas constatações relevantes para enriquecer a discussão sobre as estratégias de ingresso dos estudantes aos cursos. 
Gráfico 1 - Número de vagas ofertadas pelos Cursos de Licenciatura em Educação do Campo até 2015

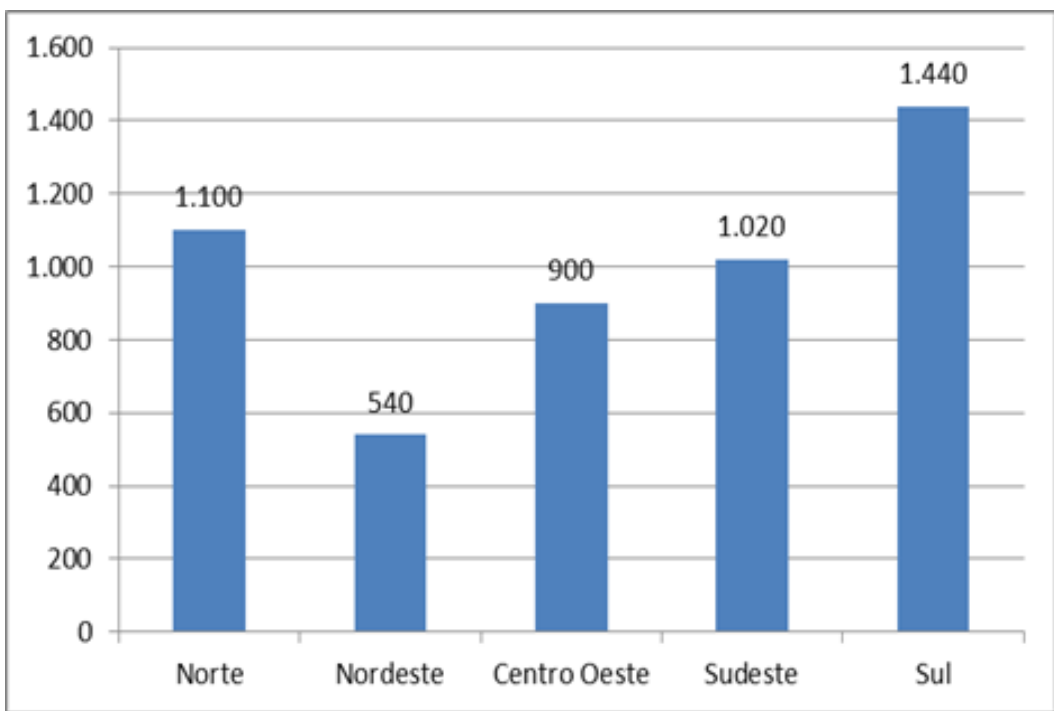

Total $=5000$ vagas.

Fonte: SECADI/MEC - com base no INEP, 2015.

Gráfico 2 - Número de vagas ocupadas pelos estudantes dos Cursos de Licenciatura em Educação do Campo até 2015

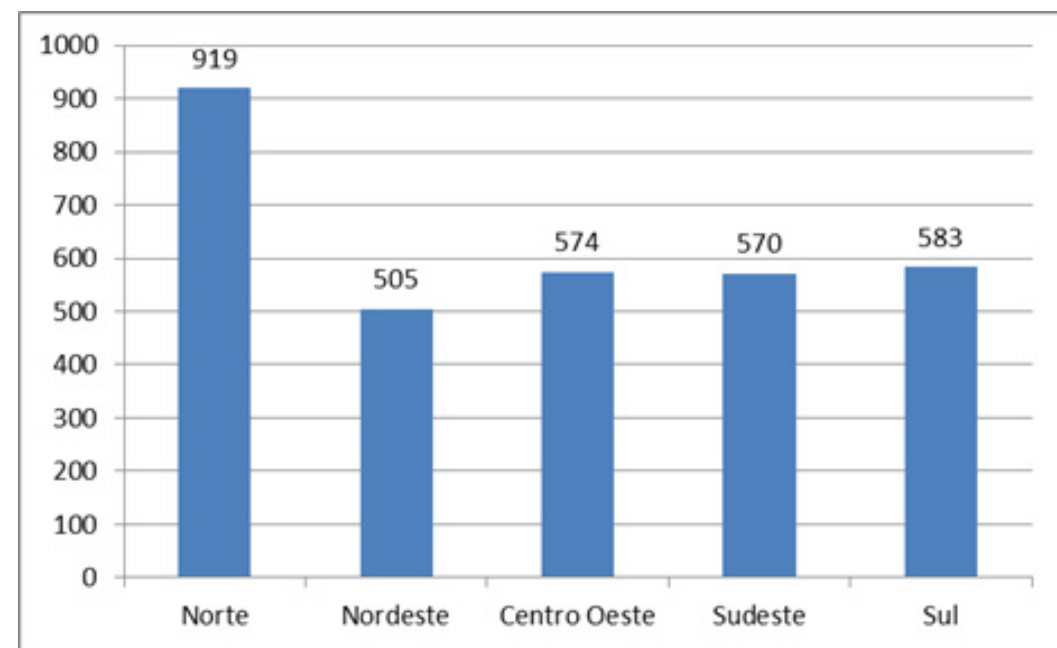

Total $=3151$ vagas.

Fonte: SECADI/MEC, com base no INEP, 2015. 
O contraste entre as vagas ofertadas (5.000) e as vagas ocupadas (3.141), resultando num índice de aproveitamento de apenas 63\%, permite-nos inferir que, mesmo que as múltiplas estratégias de ingresso ao curso postas em prática sejam determinantes para a viabilização do acesso das populações camponesas à Educação Superior, elas ainda precisam ser aprimoradas com vistas ao fortalecimento e consolidação das Licenciaturas em Educação do Campo.

Premidos pela corrente hegemônica, que entende ser o mérito o critério por excelência para assegurar a qualidade dos cursos e o ingresso de estudantes "preparados" para cursar o Ensino Superior e dar conta das atividades acadêmicas; ou pela burocracia, que, no processo de institucionalização dos cursos, justifica a impossibilidade de aplicação de estratégias alternativas aos padrões definidos pelos sistemas de gestão administrativa das instituições públicas para ocupar o total de vagas ofertadas com os sujeitos que atendam de fato o perfil desejado; o caminho para a consolidação dos cursos passa pela superação das contradições entre gestores, educadores e estudantes, objetivando assegurar os Processos Seletivos Especiais com suas estratégias diversificadas, segundo os arranjos institucionais e identitários locais.

Os gráficos permitem visualizar questões relevantes no tocante às disparidades regionais que permeiam a realidade dos cursos como, por exemplo, quando se compara no Gráfico 1 o conjunto de vagas ofertadas entre as regiões e se constata que o norte e nordeste, que possuem déficits muito mais elevados de professores do campo sem graduação, ofertam apenas 32,8\% das vagas em contraste com as demais regiões, que ofertam o dobro de vagas, ou seja, 67,2\%.

A análise dos dados que referenciam o exemplo anterior se complexifica quando os relacionamos com os dados comparativos entre os gráficos 1 e 2 e focamos o contraste entre as vagas ofertadas e ocupadas no interior de cada uma das regiões. Enquanto o Norte e o Nordeste apresentam índices de aproveitamento das vagas ocupadas de $82,8 \%$ e de $93,5 \%$ respectivamente, as regiões Centro Oeste, Sudeste e Sul, apresentam índices de apenas 63\%, 55,9\% e de $40,5 \%$ respectivamente.

É com a perspectiva de encontrar estratégias para superar estas contradições e desafios que se tem pautado o ingresso dos estudantes nos cursos de Licenciatura em Educação do Campo, para viabilizar o acesso dos sujeitos camponeses à Educação Superior. Buscam-se caminhos para superar as disputas que se forjam no interior dos cursos e das IES, tendo como perspectiva mais ampla, o avanço da democratização da Educação Superior.

$\mathrm{Na}$ próxima sessão, refletiremos sobre a utilização da Alternância Pedagógica nos cursos de Licenciatura em Educação do Campo, evidenciando 
intencionalidades e possibilidades em situações diversas experienciadas pelas universidades nos processos de formação dos educadores.

\section{CONCEPÇÃO DE ALTERNÂNCIA PEDAGÓGICA}

A alternância na Educação do Campo tem sido objeto recorrente de diversos estudos (TEIXEIRA, BERNART'T: TRINDADE, 2008; RIBEIRO, 2008), já existindo, inclusive, dissertações e teses que tratam da concepção de Alternância concebida e materializada na Licenciatura em Educação do Campo em algumas IES envolvidas na pesquisa (TRINDADE, 2011; SANTOS, 2012; BARBOSA, 2013).

Colocando a questão que, de fato, nos interessa ser refletida, a partir dos princípios do Movimento da Educação do Campo, de superar a lógica fundante da sociedade capitalista, Marlene Ribeiro (2008) nos instiga a seguir buscando compreender melhor estas contradições na concepção de alternância, ao indagar:

\footnotetext{
Mais especificamente, que possibilidades e limites a Pedagogia da Alternância, praticada pelos Movimentos Sociais Populares do Campo, apresenta para poder ser tomada como formação humana integral? [...] A discussão se faz necessária, portanto, pelo que pode contribuir para se pensar as possibilidades e os limites de se fazer educação omnilateral no estágio atual do modo de produção capitalista, e ainda, para se pensar a formação de professores direcionada a uma educação que integre trabalho e educação, na cidade e no campo. (RIBEIRO: 2008, p. 132).
}

Esta é a questão proposta pela formação em alternância, não apenas para garantir a permanência na Educação Superior daqueles que não poderiam ficar por longos períodos na universidade se desvinculando de suas comunidades camponesas, mas, pincipalmente, para integrar a produção material da vida no campo como parte relevante dos processos de aprendizagem que ocorrem nessas Licenciaturas. Isto é um complexo desafio, não só pelas condições materiais de implantação, mas também pela necessária e imprescindível compreensão e incorporação dessa intencionalidade pedagógica às práticas educativas desenvolvidas nas LEDOC pelo conjunto de educadores que atuam nos cursos, o que, sem dúvida, não é tarefa fácil, dada a própria diversidade de formação e de práticas anteriores que têm os docentes que passam a integrar esses cursos a partir dos concursos públicos.

A intencionalidade fundante da alternância concebida para formação de educadores nos Cursos de Licenciatura em Educação do Campo vincula-se ao objetivo de contribuir para promover transformações na dinâmica escolar atual, com a perspectiva de promover práticas formativas nas escolas do campo que, de fato, as transforme em lugares que contribuam para a resistência dos camponeses 
ao processo de expulsão e desterritorialização promovido pelo agronegócio. A alternância, nesse processo, é assumida como instrumento que promove o imprescindível diálogo entre os conteúdos trabalhados na Universidade, no Tempo Escola, e as tensões e contradições vivenciadas na produção material da vida dos educandos nas escolas e nos territórios do campo, no Tempo Comunidade.

A relação entre educação e trabalho, no sentido de ação humana para transformar a natureza e suprir as necessidades, faz-se estruturante desse processo. Os cursos de Licenciatura, por meio da utilização da Alternância. podem amalgamar essas dimensões, contribuindo para conceber e implementar estratégias formativas que referenciem os educadores do campo a fazerem o mesmo em seus territórios, ou seja, aliar o conhecimento cientifico aos saberes populares, produzindo um novo olhar sobre o território com a incorporação de conhecimentos mais aprofundados possibilitados pelo acesso ao conhecimento cientifico, sem se descolar desse território e, ao mesmo tempo, sem olhar de longe para ele, reconhecendo-se como protagonista e como sujeito capaz de intervir sobre essa realidade para transformá-la.

A prática da Alternância, nos cursos pesquisados, tem tido variados desenhos, tanto entre os diferentes cursos, quanto, muitas vezes, em um mesmo curso, no decorrer dos Tempos Escola e Tempos Comunidade, pois se trata de um aprendizado para as próprias universidades, que vêm buscando construir a melhor estratégia pedagógica para sua utilização. Porém, o dado mais relevante e alentador encontrado nos relatórios de pesquisa é que se identifica ampla intencionalidade de buscar a construção de estratégias que, de fato, aproximem as contradições vivenciadas pelos sujeitos camponeses no Tempo Comunidade dos conteúdos compartilhados no Tempo Escola.

Nossos estudos têm constatado nos artigos das universidades que descrevem os processos de alternância vivenciados nas Licenciaturas um esforço comum de integração do Tempo Escola com o Tempo Comunidade na formação dos educadores. Isto de dá especialmente a partir do trabalho de formá-los como sujeitos pesquisadores, capazes de inquirir suas realidades, buscando compreender, com o suporte do conhecimento científico, a essência dos processos econômicos, sociais, políticos, ambientais e culturais que ocorrem nos seus territórios. É utilizada uma série de instrumentos, de metodologias e ferramentas que lhes permitam compreender as realidades locais com mais profundidade, à medida que avançam no curso, e construir coletivamente possibilidades e condições de intervenção nessas realidades. 


\section{O relato a seguir ilustra este processo, na experiência da UFRRJ}

O Tempo Escola e o Tempo Comunidade aliam-se potencializando a relação teoria e práxis, os estudos da realidade e o colocar-se como sujeito histórico no mundo. Em ambos os tempos são realizados ensino, pesquisa e práticas pedagógicas diversas. [...] O PPP da LEDOC ainda aponta que os instrumentos pedagógicos utilizados ao longo do Tempo Comunidade são: estudos da realidade/pesquisa e práticas pedagógicas, o que inclui o mapeamento da situação educacional próxima a assentamentos da reforma agrária, áreas de pequena produção agrícola, comunidades quilombolas e caiçaras. Nestes estudos, os educandos/as podem acentuar sua formação como educador-pesquisador, realizando pesquisas e conhecendo situações pedagógicas concretas. Neste sentido, as questões históricas de sua localidade, bem como de seu município, é a base da metodologia de pesquisa, reconstruindo, assim, a totalidade das relações sociais historicamente produzidas, abrangendo a memória social, o patrimônio imaterial e físico e a dinâmica das escolas do campo. [...] A Pedagogia da Alternância pode significar uma alternativa adequada à manutenção de vínculos de trabalho coletivo e/ou familiar, assim como pode contribuir e fortalecer as lutas sociais travadas em contextos de disputas por terra, como nos processos de ocupação de grandes propriedades rurais improdutivas, na regularização fundiária, no reconhecimento de áreas remanescentes de quilombos ou em territórios expropriados das populações caiçaras. [...] No caso da Licenciatura em Educação do Campo da UFRRJ, a Pedagogia da Alternância vem se viabilizando a partir de agrupamentos estudantis de acordo com seu pertencimento territorial. Tais agrupamentos vêm sendo denominados de "Regionais". Cada Regional é coordenada e orientada por um ou mais docentes, de forma a propiciar a integração entre as diversas atividades realizadas no Tempo Escola, com o estudo da realidade local nas atividades do Tempo Comunidade, sistematizando-as e socializando-as ao término de cada etapa e nos momentos de apresentação dos Trabalhos Integrados. Estes trabalhos vão dando origem a novas pesquisas e sistematizações e, ao mesmo tempo, norteando e qualificando ações de intervenção nas localidades. (SANTOS; ABBONIZIO, 2016, p. 1634-1636).

O relato dos docentes da Licenciatura em Educação do Campo da Universidade Federal do Tocantins, no Campus de Tocantinópolis, também evidencia elementos das práticas pedagógicas em curso na formação dos educadores, que elucidam essa nova dinâmica

Nas disciplinas de Seminário Integrador, em cada semestre, é escolhido um tema gerador que articule as diferentes disciplinas e se adeque à realidade dos educandos e educandas. Cada docente prepara um roteiro com algumas perguntas, baseado na intencionalidade pedagógica de sua disciplina em conexão com o tema gerador. Dessa maneira, cada educando vai para o tempo comunidade, com cinco ou seis diferentes roteiros de questões, para refletir e pesquisar. Os dados coletados são registrados num instrumento chamado de Memorial Descritivo. Cada professor coordena e orienta um grupo de discentes, tanto na coleta de dados no tempo comunidade como posteriormente na confecção dos Memoriais Descritivos. Durante o Tempo Universidade seguinte a esta coleta de dados, os educandos em conjunto com os professores preparam seus relatórios de pesquisa Memoriais 
Descritivos para posteriormente, no final do semestre, apresentarem os resultados destas pesquisas para os demais discentes e para a comunidade. (MIRANDA, et al., 2016.)

Constata-se assim, a variada utilização de métodos e técnicas de levantamento das informações sobre o contexto dos estudantes como matéria prima para o Tempo Escola: diagnósticos participativos; inventários da realidade; temas geradores; seminários itinerantes nos territórios de origem dos educandos, com deslocamento intracampo entre eles; seminários de formação nas escolas do campo onde se inserem os educandos da LEDOC; realização de eventos sobre Educação do Campo e resistência camponesa, incluindo a presença dos movimentos sociais locais e do poder público municipal, etc. Esse processo pedagógico se dá através da formação para o uso e aprendizado desses instrumentos científicos que vão sendo produzidos, desenvolvidos e socializados em seminários integradores que ocorrem tanto nas próprias comunidades quanto nas Universidades, no Tempo Escola.

A materialização dessas experiências tem tido ampla repercussão na produção de conhecimento que se manifesta na área da Educação do Campo, situação que será analisada na seção seguinte do texto, como uma das potencialidades que emergem no âmbito dos cursos de Licenciatura em Educação do Campo envolvidos neste estudo.

\section{CONSOLIDAÇÃO DA EDUCAÇÃO DO CAMPO COMO ÁREA DE PRODUÇÃO DE CONHECIMENTO}

O processo de implantação e consolidação dos cursos de Licenciatura em Educação do Campo em todo o país tem desencadeado um rico processo de produção de conhecimento sobre esta nova proposta formativa, em diferentes níveis e dimensões. A articulação das várias especificidades da matriz formativa das LEDOC: a institucionalização da oferta da Educação Superior em Alternância; a formação por área de conhecimento, articulada à intencionalidade de promover a formação para gestão de processos educativos escolares e comunitários, a perspectiva de promover uma formação de docentes capazes de desencadear a transformação da dinâmica escolar atual têm gerado inúmeras pesquisas acerca da materialização desses princípios formativos nas várias Licenciaturas em Educação do Campo pelo país afora, em análise nesta pesquisa.

A partir do estudo Educação do Campo: Estado da Arte das Teses de 2001 a 2011, de Almeida e Chamom, (2012) identifica-se significativa ampliação de estudos sobre a formação de educadores do campo, incluindo as experiências piloto; os cursos de turmas únicas dos Editais de 2008 e 2009, e os cursos permanentes, 
que têm sido objeto de dissertações e teses, em diferentes focos: o significado e as consequências do protagonismo do movimento camponês na conquista dessa política pública; a Alternância Pedagógica; a formação interdisciplinar; a relação com as escolas do campo; a formação política e auto organização dos educandos; as intervenções das LEDOC nos territórios camponeses, sejam assentamentos, quilombos ou áreas ribeirinhas; a ampliação do acesso às novas tecnologias para os sujeitos e escolas do campo a partir dos cursos; as transformações na lógica da organização escolar e do trabalho pedagógico nas escolas do campo, conforme evidenciam os quadros a seguir.

\section{Quadro 01 - Dissertações sobre a Licenciatura em Educação do Campo}

\begin{tabular}{|c|c|c|c|}
\hline Título & Autor & Ano & IES \\
\hline $\begin{array}{c}\text { Educação do Campo e políticas públicas no Brasil: } \\
\text { a instituição de políticas públicas pelo protagonismo } \\
\text { dos movimentos sociais do campo na luta pelo direito } \\
\text { à educação }\end{array}$ & SANTOS, Clarice A. & 2010 & UnB \\
\hline $\begin{array}{c}\text { O potencial da Licenciatura em Educação do Campo } \\
\text { da Universidade de Brasilia para a produção de ações } \\
\text { contra-hegemônicas: um estudo de caso no } \\
\text { Assentamento Itaúna em Planaltina de Goiás }\end{array}$ & $\begin{array}{l}\text { TRINDADE, } \\
\text { Domingos R. }\end{array}$ & 2011 & UnB \\
\hline $\begin{array}{l}\text { Formação do Educador do Campo: um estudo a partir } \\
\text { do Procampo. }\end{array}$ & COSTA, Elaine M. & 2012 & UEPA \\
\hline $\begin{array}{l}\text { A concepção de Alternância na Licenciatura em } \\
\text { Educação do Campo na Universidade de Brasília }\end{array}$ & $\begin{array}{l}\text { SANTOS, Silvanete } \\
\text { Pereira }\end{array}$ & 2012 & UnB \\
\hline $\begin{array}{l}\text { A formação política do educador do campo: estudo } \\
\text { do curso de Licenciatura em Educação do Campo } \\
\text { da UnB }\end{array}$ & $\begin{array}{l}\text { SILVA, Julio C. } \\
\text { Pereira da }\end{array}$ & 2013 & UnB \\
\hline $\begin{array}{l}\text { A Contribuição da Organicidade na formação dos } \\
\text { educadores do território Kalunga na Licenciatura em } \\
\text { Educação do Campo da UnB }\end{array}$ & $\begin{array}{l}\text { PEREIRA, Elisangela } \\
\text { N. }\end{array}$ & 2013 & UnB \\
\hline $\begin{array}{l}\text { O que é ser educador do campo: os sentidos } \\
\text { construídos pelos estudantes do Curso de } \\
\text { Licenciatura em Educação do Campo da FaE/UFMG }\end{array}$ & ANGELO, Aline A & 2013 & UFSJ \\
\hline $\begin{array}{l}\text { Uma análise dos Projetos Políticos Pedagógicos dos } \\
\text { cursos de Licenciatura em Educação do Campo no } \\
\text { Estado do Paraná }\end{array}$ & COSTA, Gelson K.da & 2013 & UNIOESTE \\
\hline $\begin{array}{c}\text { As contribuiç̧̃es da Licenciatura em Educação do } \\
\text { Campo da UnB na transformação das relações de } \\
\text { gênero no Assentamento Vigilândia-GO }\end{array}$ & $\begin{array}{l}\text { PEREIRA, Maria de } \\
\text { Lourdes S. }\end{array}$ & 2014 & UnB \\
\hline $\begin{array}{l}\text { Formação de educadores e a construção da escola } \\
\text { do campo: um estudo sobre a prática educativa no } \\
\text { Colégio Estadual Vale da Esperança - Formosa/GO }\end{array}$ & $\begin{array}{l}\text { MACHADO, Catarina } \\
\text { dos Santos }\end{array}$ & 2014 & UnB \\
\hline $\begin{array}{l}\text { Práticas de letramentos: cartilhas das minibibliotecas } \\
\text { na formação de educadores Kalunga na Licenciatura } \\
\text { em Educação do Campo da UnB }\end{array}$ & BATISTA, Juliana A. & 2014 & UnB \\
\hline $\begin{array}{l}\text { Formação Superior em Agroecologia e Educação do } \\
\text { Campo: Práticas sociais que transbordam áreas de } \\
\text { conhecimento. }\end{array}$ & GOMES, Thiago Oliveira & 2014 & UFV \\
\hline
\end{tabular}




\section{Quadro 01 - Dissertações sobre a Licenciatura em Educação do Campo}

\begin{tabular}{|c|c|c|c|}
\hline Título & Autor & Ano & IES \\
\hline $\begin{array}{c}\text { Os desafios da Licenciatura em Educação do Campo } \\
\text { no IFPA - Campus Abaetetuba. }\end{array}$ & BENTES, Elane S. & 2014 & UFPA \\
\hline $\begin{array}{c}\text { Vídeo como ferramenta no processo formativo de } \\
\text { licenciandos em Educação do Campo }\end{array}$ & $\begin{array}{c}\text { LOPES, Eloisa A. de } \\
\text { Melo }\end{array}$ & 2014 & UnB \\
\hline $\begin{array}{c}\text { Licenciatura em Educação do Campo e movimentos } \\
\text { sociais: Análise do curso da UFMG }\end{array}$ & SOUZA, Amarildo H. & 2015 & UFV \\
\hline $\begin{array}{c}\text { Licenciatura em Educação do Campo: propostas em } \\
\text { disputa na perspectiva de estudantes do Curso de } \\
\text { Matemática da UFMG. }\end{array}$ & SÁ, Josinalva R. & 2016 & UFMG \\
\hline
\end{tabular}

Fonte: Banco de Teses \& Dissertações - CAPES: 2010-2016.

\section{Quadro 02 - Teses sobre a Licenciatura em Educação do Campo}

\begin{tabular}{|c|c|c|c|}
\hline Título & Autor & Ano & IES \\
\hline $\begin{array}{c}\text { Relativismo e escolanovismo na formação do } \\
\text { educador: uma análise histórico-crítica da Licenciatura } \\
\text { em Educação do Campo. }\end{array}$ & $\begin{array}{c}\text { SANTOS, Cláudio } \\
\text { E. F. }\end{array}$ & UFBA \\
\hline $\begin{array}{c}\text { A organização do trabalho pedagógico na Licenciatura } \\
\text { em Educação do Campo/UnB: do projeto às } \\
\text { emergências e tramas do caminhar }\end{array}$ & $\begin{array}{c}\text { BARBOSA, Anna } \\
\text { Izabel C. }\end{array}$ & 2013 & UnB \\
\hline $\begin{array}{c}\text { Novos olhares, novos significados: a formação de } \\
\text { educadores do campo }\end{array}$ & $\begin{array}{c}\text { MEDEIROS, Maria } \\
\text { Osanette de }\end{array}$ & 2013 & UnB \\
\hline $\begin{array}{c}\text { A formação de valores cooperativos e as } \\
\text { transformaçóes nas práticas educativas: um estudo } \\
\text { de caso de educandos da Licenciatura em Educação } \\
\text { do campo da UnB, no assentamento Itaúna-GO }\end{array}$ & $\begin{array}{c}\text { SILVA, Vicente de } \\
\text { Paulo B. V. }\end{array}$ & 2013 & UnB \\
\hline $\begin{array}{c}\text { Formação de Educadores e Tecnologias Digitais: } \\
\text { Relações e desafios na Licenciatura em Educação do } \\
\text { Campo da UnB }\end{array}$ & $\begin{array}{c}\text { CASTRO, Wanessa } \\
\text { de }\end{array}$ & 2014 & UnB \\
\hline $\begin{array}{c}\text { Comunicação e Tecnologias da Informação na formação de } \\
\text { educadores para ampliação das perspectivas críticas dos } \\
\text { sujeitos na Licenciatura em Educação do Campo da UnB }\end{array}$ & \begin{tabular}{c} 
FERREIRA, Márcio \\
\hline $\begin{array}{c}\text { As TIC'S na Educação do Campo: uma análise da } \\
\text { situação do Estado do Rio de Janeiro }\end{array}$
\end{tabular} & 2014 & UnB \\
\hline $\begin{array}{c}\text { Docência na escola do Campo e Formação de } \\
\text { Educadores: Qual o lugar do trabalho coletivo? }\end{array}$ & $\begin{array}{c}\text { FERREIRA, Maria } \\
\text { Jucilene L. }\end{array}$ & 2015 & UnB \\
\hline
\end{tabular}

Fonte: Banco de Teses \& Dissertações - CAPES: 2010-2016.

Um desdobramento importante nesse processo de institucionalização da LEDOC, diz respeito a mudanças no processo de produção de conhecimento, que têm sido constatadas na própria Educação Superior e não apenas na Educação Básica, como era de se esperar. Os princípios e valores da Educação do Campo têm desencadeado mudanças significativas nas instituições de ensino superior, que, de maneira geral, estão habituadas a outras regras e outros ethos: o da competição; o do trabalho individual; o da disputa; ao invés da solidariedade; 
do trabalho coletivo; do cuidado com o outro... O relato da pesquisa sobre a expansão da Educação Superior do Campo da UFV ilustra essa afirmação

O trabalho coletivo no conjunto desta equipe configura-se como uma exigência prático-teórica para gestão, construção, planejamento e desenvolvimento pedagógico do curso. No âmbito acadêmico uma série de dispositivos permanece em vigor favorecendo o trabalho individual, competitivo, solitário, reafirmando o mérito pessoal em detrimento dos elos coletivos. Essas características constitutivas e mantenedoras da sociedade capitalista repercutem nas práticas pedagógicas, que acabam por reforçá-las, ensinando, valorizando e reafirmando o sistema vigente. Atentar para essas questões sem reproduzi-las é fundamental em processos educativos que se propõem questionadores e transformadores da sociedade, como é o caso da formação de educadores do campo. Nesse sentido o trabalho coletivo dos educadores da LEDOC apresenta traços de contra hegemonia. Tal coletividade se manifesta em diferentes instâncias como: a organização geral e planejamento pedagógico do curso, com a totalidade dos educadores envolvidos e ainda a presença de pessoas colaboradoras e professores de outros cursos; na implementação de um conselho de cooperação do curso, composto por representantes dos movimentos sociais; as atividades de coordenação, realizadas por uma comissão composta por quatro membros; o planejamento e desenvolvimento dos conteúdos disciplinares do curso que envolve pelo menos dois educadores. [...] visando otimizar este trabalho coletivo, o grupo de educadores realiza imersões pedagógicas, reuniões semanais envolvendo questões pedagógicas e administrativas e também encontros de estudos e planejamentos articulados ao Núcleo Docente Estruturante (NDE), respeitando as atividades calendarizadas de Tempo Escola e acompanhamento de Tempo-Comunidade. (MARQUES et al, 2016; p. 1667).

Apesar das inúmeras dificuldades e incertezas que a formação por área de conhecimento provoca nos docentes da LEDOC, que se desafiam, de fato, a promover uma formação interdisciplinar, uma significativa mudança positiva, ela produz, exige e promove o trabalho coletivo dos educadores. Conceber e executar a formação por área de conhecimento, pensando a interdisciplinaridade como exigência da própria materialidade; da complexidade dos problemas da realidade que se quer compreender e explicar exige, fundamentalmente, o trabalho coletivo. Assim, o que começa como exigência acaba evoluindo para escolhas em outras áreas do trabalho acadêmico, originando muitas pesquisas e projetos de extensão vinculados à LEDOC, que têm por base o trabalho coletivo dos educadores e educandos. Isso nos possibilita afirmar que está em processo nos cursos de Licenciatura em Educação do Campo acompanhados pela pesquisa um rico trabalho de ressignificação da prática docente no âmbito da Educação Superior, onde o trabalho coletivo assume centralidade, tanto na organização das práticas pedagógicas quanto no próprio processo de produção de conhecimento.

E para concluir a reflexão, neste momento em que nos propusemos compreender os riscos e potencialidades que se materializam durante o processo de institucionalização da Licenciatura em Educação do Campo nas instituições 
investigadas, ressaltamos a importância de fortalecer os embates e disputas no interior dos cursos, envolvendo coordenadores, docentes e estudantes em parceria com os movimentos sociais para que, via Processos Seletivos Especiais, com a utilização de estratégias diversificadas e critérios definidos, possamos assegurar o ingresso de sujeitos identificados com o perfil que se pretende atingir e, com isso, consolidar o curso e avançar na democratização da Educação Superior no Campo. Nos cursos investigados, a Alternância Pedagógica se tem revelado por meio de variados desenhos como possibilidade de integração do Tempo Escola com o Tempo Comunidade na formação dos educadores, resultantes da experimentação e aprendizado das próprias universidades na ação de construir estratégias que aproximem as situações vivenciadas pelos sujeitos camponeses em seus territórios e comunidades dos conteúdos e aprendizados compartilhados no interior da universidade. Esse processo tem contribuído para formar os educadores como sujeitos pesquisadores, capazes de inquirir suas realidades para compreender com o apoio dos conhecimentos científicos, a complexidade dos processos econômicos, sociais, políticos, ambientais e culturais que se manifestam nos seus territórios e de construir coletivamente possibilidades e condições de intervenção nessas realidades.

Essas múltiplas formas de construir e vivenciar a materialização dos princípios e práticas formativas do Curso de Licenciatura em Educação do Campo nas universidades investigadas, como também em todo o país, tem desencadeado um amplo e rico processo de produção de conhecimento sobre essa nova proposta formativa, em diferentes níveis e dimensões, seja com a utilização da Alternância Pedagógica ou por meio da formação por área de conhecimento, seja com a formação de educadores para atuar na escola básica ou nas experiências educativas que se efetivam nas comunidades e territórios do campo.

Sem desconsiderar as dificuldades e incertezas que os cursos enfrentam nas universidades, múltiplos trabalhos de conclusão de graduação, monografias, dissertações e teses têm sido construídos com a perspectiva de dar visibilidade às mudanças positivas que têm sido efetivadas, contribuindo para consolidar a Licenciatura em Educação do Campo. Nesses estudos, o trabalho coletivo de ducadores e educandos assume centralidade, tanto na organização das práticas pedagógicas quanto no processo de produção de conhecimento, enquanto exigência para dar conta da compreensão dos problemas da realidade dos territórios rurais e da intervenção nessa mesma realidade com a perspectiva de transformá-la. 


\section{REFERÊNCIAS}

ALMEIDA, Antonia Lucineire; CHAMOM, Edna Maria Querido de Oliveira. Educação do Campo: Estado da Arte das Teses de 2001 a 2011. In: Congresso Internacional Interdisciplinar e Sociais E Humanidades, Niterói. Anais... Rio de Janeiro: ANINTER-SH/ PPGSD-UFF, 2012.

ANGELO, Aline A. O que é ser educador do campo: os sentidos construídos pelos estudantes do Curso de Licenciatura em Educação do Campo da FaE/ UFMG. 2013.150p. Dissertação (Mestrado em Educação) - Universidade Federal de São João del Rei, São João del Rei-MG, 2013.

ANJOS, Maura Pereira dos; SILVA, Maria Célia Vieira da; MOLINA, Mônica Castagna. Materialização da licenciatura em educação do campo: reflexões a partir da alternância pedagógica. In: XXIV Seminário Nacional Universitas/Br, 24., Maringá. Anais... . Maringá: Rede Universitas/Br, 2016. p. 1825-1842. Disponível em: <http://www.ppe.uem.br/xxivuniversitas/anais/trabalhos/Anais_textos_ completos.pdf>. Acesso em: 20 set.2016.

BARBOSA, Anna Isabel C. A organização do trabalho pedagógico na Licenciatura em Educação do Campo/UnB: do projeto às emergências e tramas do caminhar. 2013. 352p. Tese Doutorado em Educação) - Universidade de Brasília, Brasília. 2013.

BATISTA, Juliana A. Práticas de letramentos: cartilhas das minibibliotecas na formação de educadores Kalunga na Licenciatura em Educação do Campo da UnB. 2014. 121p. Dissertação (Mestrado em Educação) Universidade de Brasília, Brasília, 2014.

BENTES, Elane S.. 2014. Os desafios da Licenciatura em Educação do Campo no IFPA - Campus Abaetetuba. 128p. Dissertação (Mestrado em Educação) - Universidade Federal do Pará, Belém, 2014.

BRASIL. Decreto $\mathbf{n}^{\mathbf{0}} \mathbf{7 . 3 5 2}$, de 04 de dezembro de 2010. Dispõe sobre a política de Educação do Campo e o Programa Nacional de Educação na Reforma Agrária - Brasilia: Imprensa Nacional, 2010. Disponível em: < http://www.planalto. gov.br/ccivil_03/_ato2007-2010/2010/decreto/d7352.htm>. Acesso em: 17 mar.2015. 
.SESu/SETEC/SECADI. Edital n ${ }^{\circ}$ 02, de 31 de agosto de 2012. Chamada Pública para seleção de IFES e IFET, para criação de cursos de Licenciatura em Educação do Campo. Brasília: Imprensa Nacional: 2012.

CASTRO, Wanessa de. Formação de Educadores e Tecnologias Digitais: Relações e desafios na Licenciatura em Educação do Campo da UnB. 2014. 241p. Tese (Doutorado em em Educação) - Universidade de Brasília, 201

COSTA, Elaine M. Formação do Educador do Campo: um estudo a partir do Procampo. 2012. 208p. Dissertação (Mestrado em Educação) - Universidade Estadual do Pará. Belém, 2012.

COSTA, Gelson K.da. Uma análise dos Projetos Políticos Pedagógicos dos cursos de Licenciatura em Educação do Campo no Estado do Paraná. 2013. 110p. Dissertação (Mestrado em Educação) - Universidade Estadual do Oeste do Paraná. -PR, 2013

FERREIRA, Márcio. Comunicação e Tecnologias da Informação na formação de educadores para ampliação das perspectivas críticas dos sujeitos na Licenciatura em Educação do Campo da UnB. 2014. 296p. Tese (Doutorado em Educação) - Universidade de Brasília, 2014.

FERREIRA, Maria Jucilene L. Docência na escola do Campo e Formação de Educadores: Qual o lugar do trabalho coletivo? 2015.238p. Tese (Doutorado em Educação) - Universidade de Brasília, 2015

GOMES, Thiago Oliveira. Formação Superior em Agroecologia e Educação do Campo: Práticas sociais que transbordam áreas de conhecimento. 2014. 132p. Dissertação (Mestrado em Educação) - Universidade Federal de Viçosa, 2014.

IPEA. II PNERA. Relatório da II Pesquisa Nacional sobre a Educação na Reforma Agrária. Brasília: Ministério do Desenvolvimento Agrário, Jun. 2015.

INEP. Censo da Educação Superior 2015. IN: http://sistemascensosuperior. inep.gov.br/censosuperior_2015/. Acesso em 10/09/2016.

LOPES, Eloisa A. de Melo. Vídeo como ferramenta no processo formativo de licenciandos em Educação do Campo. 2014.139p. Dissertação (Mestrado em Educação) - Universidade de Brasília, Brasília, 2014. 
MACHADO, Catarina dos Santos. Formação de educadores e a construção da escola do campo: um estudo sobre a prática educativa no Colégio Estadual Vale da Esperança - Formosa/GO. Dissertação (Mestrado em Educação) Universidade de Brasília, Brasília, 2014

MARQUES, Emiliana Maria Diniz et al. Concepções e práticas da Licenciatura em Educação do Campo/LICENA/UFV. In: XXIV Seminário Nacional Universitas/Br, 24., Maringá. Anais... . Maringá: Rede Universitas/Br, 2016. p. 1661-1674.. Disponível em: <http://www.ppe.uem.br/xxivuniversitas/anais/ trabalhos/Anais_textos_completos.pdf $>$. Acesso em: 20 set.2016.

MARTINS-AUGUSTO, Katja P. C. As TIC'S na Educação do Campo: uma análise da situação do Estado do Rio de Janeiro. 2014. 363p. Tese (Doutorado em Educação) - Universidade Federal Rural do Rio de Janeiro, 2014.

MEDEIROS, Maria Osanette de. Novos olhares, novos significados: a formação de educadores do campo. 2013. 252p. Tese (Doutorado em em Educação) - Universidade de Brasília, 2013

MIRANDA , Cássia Ferreira ett all. Caminhos e Horizontes da Licenciatura em Educação do Campo na Região do Bico do Papagaio. Apresentação no In: XXIV Seminário Nacional Universitas/Br, 24., Maringá. Anais... . Maringá: Rede Universitas/Br, 2016. p. 1661-1674.

MOLINA, Mônica C. Expansão das Licenciaturas em Educação do Campo: desafios e potencialidades. Educar em Revista, Curitiba, Brasil, n. 55, p. 145 166, jan./mar. 2015.

MOLINA, Mônica Castagna; HAGE, Salomão. Política de formação de educadores do campo no contexto da expansão da educação superior. Revista Educação em Questão, Natal, v. 51, n. 37, p. 121-146, jan./abr. 2015.

PEREIRA, Elisangela N. A Contribuição da Organicidade na formação dos educadores do território Kalunga na Licenciatura em Educação do Campo da UnB. 2013. 93p. Dissertação (Mestrado em Educação) - Universidade de Brasília, Brasília, 2013. 
PEREIRA, Maria de Lourdes S. As contribuições da Licenciatura em Educação do Campo da UnB na transformação das relações de gênero no Assentamento Vigilândia-GO. 2014. 94p. Dissertação (Mestrado em Educação) - Universidade de Brasília, Brasília, 2014.

RIBEIRO, Marlene. Contradições na relação trabalho-educação do campo: a Pedagogia da Alternância. Trabalho \& Educação, v.17, n. 2, p. 131-144, maio / ago. 2008. Disponível em:< http://www.portal.fae.ufmg.br/revistas/index.php/ trabedu/article/download/335/304>. Acesso em: 20 set. 2016.

SÁ, Josinalva R. Licenciatura em Educação do Campo: propostas em disputa na perspectiva de estudantes do Curso de Matemática da UFMG. 20162016.

SANTOS, Clarice A. Educação do Campo e políticas públicas no Brasil: a instituição de políticas públicas pelo protagonismo dos movimentos sociais do campo na luta pelo direito à educação. 2010.109p. Dissertação (Mestrado em Educação) - Universidade de Brasília, Brasília, 2010.

SANTOS, Cláudio E. F. Relativismo e escolanovismo na formação do educador: uma análise histórico-crítica da Licenciatura em Educação do Campo. 2011. 268p. Tese (Doutorado em em Educação) - Universidade Federal da Bahia, Salvador, Bahia, 2011.

SANTOS, Ramofly Bicalho dos; ABBONIZIO, Aline. A Pedagogia da Alternância e a Licenciatura em Educação do Campo na UFRRJ. In: XXIV Seminário Nacional Universitas/Br, 24., Maringá. Anais... . Maringá: Rede Universitas/Br, 2016. p. 1631-1644. Disponível em: <http://www.ppe.uem.br/xxivuniversitas/ anais/trabalhos/Anais_textos_completos.pdf $>$. Acesso em: 20 set.2016.

SANTOS, Silvanete Pereira. A concepção de Alternância na Licenciatura em Educação do Campo na Universidade de Brasília. 2012, 163p. Dissertação (Mestrado em Educação) -Universidade de Brasília. Brasília, 2012.

SILVA, Júlio C. Pereira da, A formação política do educador do campo: estudo do curso de Licenciatura em Educação do Campo da UnB. 
SILVA, Vicente de Paulo B. V. A formação de valores cooperativos e as transformações nas práticas educativas: um estudo de caso de educandos da Licenciatura em Educação do campo da UnB, no assentamento Itaúna-GO. 2013. 263p. Tese (Doutorado em Educação) - Universidade de Brasília, 2013

SOUZA, Amarildo H. Licenciatura em Educação do Campo e movimentos sociais: Análise do curso da UFMG. 2014. 156p. Dissertação (Mestrado em Educação) - Universidade Federal de Viçosa, Viçosa-MG, 2014.

TEIXEIRA, Edival Sebastião; BERNART'T, Maria de Lourdes; TRINDADE, Glademir Alves. Estudos sobre Pedagogia da Alternância no Brasil: revisão de literatura e perspectivas para a pesquisa. Educação e Pesquisa, São Paulo, v.34, n.2, p. 227-242, maio/ago. 2008.

TRINDADE, Domingos R. 2011 O potencial da Licenciatura em Educação do Campo da Universidade de Brasília para a produção de ações contrahegemônicas: um estudo de caso no Assentamento Itaúna em Planaltina de Goiás. 168p. Dissertação (Mestrado em Educação) - Universidade de Brasília, Brasília, 2011.

TRINDADE, Domingos Rodrigues. A alternância como elo articulador na formação de educadores e educadoras do campo. Cadernos Ceru, série 2, v. 22, n. 1, p.257-267, jun. 2011.

O potencial da Licenciatura em Educação do Campo da Universidade de Brasília para a produção de ações contra hegemônicas: um estudo de caso no Assentamento Itaúna em Planaltina de Goiás. (2011). 168p. Dissertação (Mestrado em Educação) - Universidade de Brasília, Brasília, 2011.

MÔNICA CASTAGNA MOLINA é doutora em Desenvolvimento Sustentável pela Universidade de Brasília (2003), com Pós-Doutorado em Educação pela Universidade Estadual de Campinas (2013). É professora adjunta da Universidade de Brasília (UnB), atuando como Professora do Programa de PósGraduação em Educação. Diretora do Centro Transdisciplinar de Educação do Campo e Desenvolvimento Rural e Coordenadora do Grupo de Trabalho de Apoio à Reforma Agrária. Coordenadora da Pesquisa "Educação do Campo e Educação Superior: uma análise de práticas contra-hegemônicas na formação de profissionais da Educação e das Ciências Agrárias nas regiões Centro-Oeste, 
Nordeste e Norte". Pesquisadora da Rede Universitas/Br, na qual participa do Observatório da Educação "Políticas de Expansão da Educação Superior no Brasil”. E-mail: mcastagnamolina@gmail.com

SALOMÃO MUFARREJ HAGE é doutor em Educação pela Pontifícia Universidade Católica de São Paulo (2000). É professor do Instituto de Ciências da Educação da Universidade Federal do Pará e docente do Programa de PósGraduação em Educação e do Programa de Linguagens e Saberes da Amazônia. É bolsista produtividade do CNPq. Coordena o Grupo de Estudo e Pesquisa em Educação do Campo na Amazônia. Integra a Coordenação do Fórum Paraense de Educação do Campo e Coordena a Escola de Conselhos Pará: Núcleo de Formação Continuada de Conselheiros Tutelares e de Direitos da Amazônia Paraense. É pesquisador da Rede Universitas/Br, na qual participa do Observatório da Educação "Políticas de Expansão da Educação Superior no Brasil”. E-mail: salomao_hage@yahoo.com.br 